\title{
Capturing community influence on public preparedness
}

\author{
F. Petit, R. Fisher, J. Yaeger \& M. Collins \\ Infrastructure Assurance Center, Argonne National Laboratory, USA
}

\begin{abstract}
Regardless of the measures put in place to prevent or mitigate them, natural and man-made hazards remain a daunting challenge for community leaders tasked with ensuring public safety. Governments and other organizations can provide services to protect and respond to their citizens' needs in an emergency, but ultimately, the relative resilience of a community relies, to a large extent, on the preparedness of the individuals living within it. While individual preparedness is determined largely by personal attributes, another important determinant is the influence of the community on the knowledge base and available resources of its members. To capture the influence that a community can have on instilling and increasing preparedness competencies in its population, Argonne National Laboratory has developed a public preparedness index. The index captures aspects such as disaster public education programs, crisis communication, public communication, citizen preparedness groups, and additional resources such as community shelters and evacuation routes/plans. This index allows community leaders to (1) better understand how well they are equipping their citizens to face potential hazards and (2) identify areas for improvement. As increased emphasis is placed on better equipping communities to face potential hazards, it is vital that those communities also understand how their actions affect the preparedness of their citizens.
\end{abstract}

Keywords: emergency management, public preparedness, regional resilience, critical infrastructures.

\section{Introduction}

The assessment of community resilience is complex because the term needs to characterize the resilience of organizations and infrastructures, as well as the 
resilience of "softer" aspects, like the individual resilience of citizens [1]. Multiple definitions and methodologies have been developed to assess these aspects of community resilience [2-4]. While the methodologies differ in terms of their precise approach, all emphasize the need to characterize the abilities of a community to sense, evaluate, and adapt to post-disaster consequences [5]. Thus, regional resilience is properly defined as the performance of a region in managing (protecting, mitigating, responding and recovering from) an emergency or a disaster by considering the capabilities of different subsystems. These subsystems include the following:

- Ecological subsystem - combines biological and physical elements of the environment in which a community is located;

- Economic subsystem - comprises people, firms, and institutions that interact to produce, distribute, and consume goods and services;

- Governance subsystem - includes the public and private organizations that contribute to the administration of governmental functions of the community;

- Physical infrastructure subsystem - the substructure or underlying foundation or network used for providing goods and services; and

- Civil society subsystem - the formal and informal modes of social organization and collective action outside of governmental authority.

Consideration of all these subsystems is necessary to assess the ability of a region or system to respond to and recover from natural or human-caused hazards. However, the following elements are often underestimated or underevaluated when considering the resilience of a region: the evaluation of the Nation's progress on personal preparedness and individual response, as well as the measure of the public's knowledge, attitudes, and behaviors in preparing for a range of hazards. The resilience of the civilian population is often referred to by different terms, such as civil society resilience, community capital resilience, community competence, social capital, and social resilience; these terms focus, to varying degrees, on the ability of the general public within a community to prepare for and respond to a disturbance. The public's inability to adapt, respond to, and recover from a disturbance will seriously limit the community's ability to bounce back, regardless of the resiliency of the other subsystems (listed above), because individuals are necessary for a community to exist at its most basic level and are necessary components of the other subsystems.

Argonne National Laboratory, in partnership with the Department of Homeland Security (DHS), has developed an index to characterize public preparedness that can be combined with other indices that characterize the resilience of each individual community subsystem. These indices are based on a comprehensive methodology already in use to characterize the vulnerability and resilience of critical infrastructures $[2,6]$. This paper presents the main principles of this methodology and describes how it is used to assess public preparedness and the impact that a community has on increasing individual resilience capabilities. 


\section{Citizen preparedness}

Public preparedness in an emergency is a major concern in the United States, as demonstrated by the amount of money spent to educate the public [7], as well as by the numerous awareness campaigns supported by different organizations and Web sites such as Ready.gov, 72hours.org, or AlertChicago.org [8-10].

Furthermore, numerous surveys, such as the 2009 Citizen Corps National Survey conducted by Citizen Corps, in partnership with the Federal Emergency Management Agency of DHS, have evaluated the readiness of citizens and highlighted the need for them to be better prepared to face an emergency [11]. These studies are useful in the sense that they provide statistics about the awareness and preparedness of the population and allow public officials to identify existing gaps in that preparation. Nevertheless, these studies do not provide communities with a comprehensive and consistent tool to measure how prepared their citizens are (on a community, rather than aggregate national, scale) and to define what they can do to increase their citizens' level of resilience [7].

To address this issue, different tools have been developed. One of these, the public readiness index $(\mathrm{PRI})$ - developed by the Council for Excellence in Government - provides a value that allows officials to define the preparedness of a population and compare the preparedness levels of different communities [7]. While useful, this index is based on only ten questions and is focused on the community members and their current knowledge or actions, and not on their potential through community programs or resources [7]. The index does not really allow officials to define how the community can prepare the population for an emergency or identify the functions and options that a community can use to enhance the readiness of its citizens.

Thus, existing tools such as the PRI are useful in terms of the limited information they provide; however, they are not sufficient to assess, in its entirety, the citizens' level of preparation and its contribution to regional resilience. To do this, officials need to be able to measure the ability of a community to support the preparedness of its citizens. This task tends to be complex because directly measuring all the variables that support all the operational preparedness and response functions of an individual can be difficult and time consuming.

To solve these issues, the tool developed by Argonne and DHS uses proxy variables to capture the main functions and characteristics of a community that support or increase the preparation of the population facing an emergency. Instead of characterizing the ability of a community or a population to react to different specific events, the proxy variables consider the elements that contribute to increased preparation and the resources necessary to allow individuals to maximize their use of that knowledge, regardless of which individuals inhabit the community. Using these proxy variables will allow assessors to more quickly conduct the study and still reach a valid conclusion.

A top-down approach, based on the principles of functional analysis and multiattribute utility theory [12], is used to define the main elements of the Public Preparedness Index (PPI). This index is organized into four levels of information. 
- The first level corresponds to main community functions, which regroup the actions a community should take to support public preparedness.

- The second level corresponds to components, which regroup the elements a community should have to support their main functions.

- The third level corresponds to activities, which regroup the different tasks that constitute the community components.

- The fourth level corresponds to the characteristics of the activities.

The functional analysis, developed by subject matter experts (SMEs), defines a tree organization of the community elements that support public preparedness from the functions to the characteristics. Table 1 shows the eight level 1 functions and the 24 level 2 components of the PPI.

Table 1: $\quad$ Two first levels of the PPI.

\begin{tabular}{|c|c|}
\hline Level 1: Functions & Level 2: Components \\
\hline Disaster public education programs & $\begin{array}{ll}- & \text { Hazard identification } \\
\text { - } & \text { Risk assessment } \\
\text { - } & \text { Hazard awareness } \\
\text { - } & \text { Training } \\
\text { Resources }\end{array}$ \\
\hline Public information & $\begin{array}{ll}\text { - } & \text { Crisis communication } \\
\text { - } & \text { Risk communication } \\
\text { - } & \text { Public point of contact }\end{array}$ \\
\hline Public health programs & $\begin{array}{ll}\text { - } & \text { Disease prevention/control } \\
\text { - } & \text { Food safety } \\
\text { - } & \text { Health education }\end{array}$ \\
\hline Health care & $\begin{array}{ll} & \text { Medical assets } \\
- & \text { Surge capability } \\
\text { - } & \text { Mass casualty } \\
\end{array}$ \\
\hline Community engagement & $\begin{array}{l}\text { - } \quad \text { Public/private partnerships } \\
\text { - } \quad \text { Citizens groups/organizations }\end{array}$ \\
\hline Warning/notifications systems & $\begin{array}{ll}- & \text { Disaster warning systems } \\
\text { - } & \text { Public notification systems } \\
\text { - } & \text { Health alert systems }\end{array}$ \\
\hline Evacuation resources & $\begin{array}{ll}\text { - } & \text { Evacuation plans } \\
\text { - } & \text { Evacuation routes }\end{array}$ \\
\hline Community shelters & $\begin{array}{ll}\text { - } & \text { Community shelter } \\
\text { management plan } \\
\text { - } \\
\text { Evacuee shelter management } \\
\text { plan } \\
\text { - } \quad \text { Facilities }\end{array}$ \\
\hline
\end{tabular}


Level 2 components are subdivided into their essential activities. For example, crisis communication, a level 2 component of public information (level 1), combines seven level 3 activities. One of these activities is monitoring events, which can be characterized by using five questions, which constitute level 4 information (Table 2).

The survey questions, to be answered by a yes or a no, are developed to return pertinent information that will support the calculation of the PPI.

Table 2: $\quad$ Levels 3 and 4 of PPI, under crisis communication (level 2) and public information (level 1).

\begin{tabular}{|c|c|}
\hline \multicolumn{2}{|c|}{ Level 2: Crisis communication } \\
\hline Level 3: Activities & Level 4: Characteristics \\
\hline Monitoring of events & $\begin{array}{l}\text { Following a crisis, is there a process in } \\
\text { place to conduct: } \\
\text { - Ongoing media monitoring? } \\
\text { - } \quad \text { Externet monitoring? } \\
\text { internal and external } \\
\text { organizations, including state } \\
\text { health departments, etc.? } \\
\text { Ongoing communication with } \\
\text { SMEs and stakeholders? } \\
\text { - Monitoring of public opinion? }\end{array}$ \\
\hline
\end{tabular}

Organization of all the information that characterizes the ability of a community to support public preparedness provides officials with a means to obtain an overall index; such an index allows comparison of the preparation levels of individuals in different communities. Indeed, all levels of information can be aggregated to define the level above and, ultimately, to calculate a PPI that represents the capabilities of a community to support the preparation of its citizens.

Section 3 explains how the data characterizing public preparedness can be captured and aggregated to define a PPI that characterizes the support of a community and, ultimately, regional resilience.

\section{Index methodology}

The index methodology developed by Argonne and DHS allows comparison of the functions and actions undertaken by a community to increase the individual preparedness of its citizens. This methodology comprises three steps:

- Collection of data;

- Definition of public preparedness on the basis of data collected;

- Visualization of the capabilities of a jurisdiction and comparison to other like jurisdictions. 


\subsection{Data collection}

The main components that characterize the community capabilities to support public preparedness are defined by using a top-down approach - from the functions of the community to the characteristics of activities needed to fulfill those functions. However, only the information in the fourth level (characteristics) needs to be collected. The other levels of information are calculated on the basis of the aggregation of the fourth-level characteristics. Data are collected through a questionnaire that captures the most important information characterizing community capabilities in a given jurisdiction. The questionnaire was developed in collaboration with SMEs and based on existing surveys characterizing public preparedness, individual response capabilities, and social resilience. Through the use of objective questions (e.g., the presence of a specific plan or resource), the survey ensures the collection of accurate and transparent information that can be compared and interpreted in a consistent manner. The questionnaire was developed to be completed by individuals in charge of the various service functions within a community and to be completed in a limited amount of time. The survey covers the eight core functions of a community to support public preparedness considering a possible catastrophic event. The information required to complete the PPI is collected during an onsite assessment visit; however, a self-assessed PPI score could also be derived if deemed appropriate. In this case, the data would be obtained from a survey that corresponds to the variables in the index and that could be modified to reflect future changes.

The next section describes how the data collected are used to calculate the PPI.

\subsection{Calculation of the PPI}

Each question (level 4), and each component and subcomponent of the PPI, is assigned a weight representing its relative importance compared with other questions/components/subcomponents in its grouping. The weights were obtained in accordance with the principles of "decision analysis," an approach that helps manage risk under conditions of uncertainty [13, 14]. The methodology is based on a numerical representation of the value pattern obtained by comparing different elements of a jurisdiction and by using relations "better than" and "equal in value to" to define their relative importance. Another important element in this decision analysis tool is the transitivity of the ranking, i.e., if an element $\mathrm{A}$ is more important than an element $\mathrm{B}$, and an element $\mathrm{B}$ is more important than an element $\mathrm{C}$, then logically $\mathrm{A}$ will be more important than C. This approach produces a relational representation of capabilities alternatives by providing a numerical value assignment for each of its components. The weights for a set of components depend on the ranges (worst to best) that are included as options in the question set.

Table 3 shows an example of the results of that process, completed by three groups of experts, for components of monitoring an event, a subcomponent of crisis communication, which is a component of public information. 
Table 3: $\quad$ Example of value assessments from experts (illustrative).

\begin{tabular}{|c|c|c|c|c|c|c|c|}
\hline \multicolumn{8}{|c|}{ Public information - Crisis communication - Monitoring event } \\
\hline \multirow{2}{*}{$\begin{array}{l}\text { Following a crisis, } \\
\text { is there a process } \\
\text { in place to } \\
\text { conduct: }\end{array}$} & \multicolumn{2}{|c|}{ Group 1} & \multicolumn{2}{|c|}{ Group 2} & \multicolumn{2}{|c|}{ Group 3} & \multirow[b]{2}{*}{ 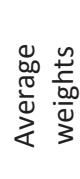 } \\
\hline & 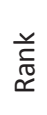 & $\begin{array}{l}\frac{ \pm}{c} \\
\frac{.000}{0} \\
3\end{array}$ & 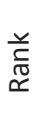 & $\frac{\frac{\pi}{5}}{\frac{0.00}{0}}$ & 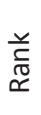 & 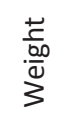 & \\
\hline $\begin{array}{l}\text { Ongoing media } \\
\text { monitoring? }\end{array}$ & 1 & 100 & 1 & 100 & 1 & 100 & 100 \\
\hline $\begin{array}{l}\text { Internet } \\
\text { monitoring? }\end{array}$ & 2 & 90 & 4 & 70 & 4 & 80 & 80 \\
\hline $\begin{array}{l}\text { Exchanges of } \\
\text { information with } \\
\text { internal and } \\
\text { external } \\
\text { organizations? }\end{array}$ & 1 & 100 & 2 & 95 & 3 & 85 & 93.33 \\
\hline $\begin{array}{l}\text { Ongoing } \\
\text { communication } \\
\text { with SMEs and } \\
\text { partners? }\end{array}$ & 3 & 80 & 3 & 75 & 2 & 90 & 81.67 \\
\hline $\begin{array}{l}\text { Monitoring of } \\
\text { public opinion } \\
\text { data and other } \\
\text { research? }\end{array}$ & 5 & 70 & 5 & 65 & 5 & 70 & 68.33 \\
\hline
\end{tabular}

In the index, five answers are possible to characterize the monitoring of an event. Each group of experts ranks each of these elements in relation to the others, from 1 (most important element) to 5 (least important element). If the SMEs decide that two elements have the same importance, they can give them the same rank. Subsequently, the element ranked first is attributed a weight of 100. Each group defines the weight of each other element in the grouping, considering its relative rank and importance to the element ranked first. The weights of two elements can be equal if these elements have the same importance or they can be relatively close if the elements are not of equal importance but are separated by only a slight increase in value. Conversely, the difference in weights can be large between two elements if one is considered significantly less important than another.

Table 3 shows that the three groups of experts rank ongoing media monitoring as the most important element to consider in the event monitoring variable. For Group 1, this element has the same importance as the exchange of information with internal and external organizations and is also ranked first. For all groups, monitoring of public opinion is the least important variable compared with the other possibilities. However, although the three groups ranked the variables differently, the weights defined do not vary significantly. Indeed, for this part of the PPI, the weights vary only from 65 to 100, which means that although media monitoring may be considered the most important element, the other four possibilities are also significantly important for optimal event 
monitoring. Finally, when all experts' ranks and weights are defined for a specific subcomponent group's level, final weights are obtained by using an average of weights. For the event monitoring variable, the final weights vary from 100 for the most important elements to 68.33 for the relatively least important. In the example, the answers are not exclusive. The best plan is the one that integrates all of the components, and it should correspond to a value of 100 . It is then necessary to redefine the combined weights of all plan components to obtain a value of 100 when they are summed (Table 4).

Table 4: $\quad$ Final weights for event monitoring (illustrative).

\begin{tabular}{|l|c|c|}
\hline $\begin{array}{l}\text { Following a crisis, is there a process in place } \\
\text { to conduct: }\end{array}$ & Average Weights & $\begin{array}{c}\text { Final Proportional } \\
\text { Weight }\end{array}$ \\
\hline Ongoing media monitoring? & 100 & 23.62 \\
\hline Internet monitoring? & 80 & 18.90 \\
\hline $\begin{array}{l}\text { Exchanges of information with yours and } \\
\text { other organization? }\end{array}$ & 93.33 & 22.05 \\
\hline $\begin{array}{l}\text { Ongoing communication with SMEs and } \\
\text { partners? }\end{array}$ & 81.67 & 19.29 \\
\hline $\begin{array}{l}\text { Monitoring of public opinion data and other } \\
\text { research? }\end{array}$ & 68.33 & 16.14 \\
\hline Sum & 423.33 & 100 \\
\hline
\end{tabular}

With these weights, it is possible to calculate a community's value for the event monitoring variable. A value of 100 is attributed to a variable when the corresponding question is answered affirmatively. A value of 0 is attributed to a negative answer. The value of the group is then obtained by using a weighted sum of all component values in a group, such as the one in Table 5.

Table 5: $\quad$ Monitoring event value (illustrative).

\begin{tabular}{|c|c|c|c|c|}
\hline $\begin{array}{c}\text { Following a crisis, is } \\
\text { there a process in } \\
\text { place to conduct: }\end{array}$ & Answer & Value & Weight in \% & Weighted value \\
\hline $\begin{array}{c}\text { Ongoing media } \\
\text { monitoring? }\end{array}$ & Yes & 100 & 0.2362 & 23.62 \\
\hline Internet monitoring? & No & 0 & 0.1890 & 0 \\
\hline $\begin{array}{c}\text { Exchanges of } \\
\text { information with } \\
\text { yours and other } \\
\text { organization? }\end{array}$ & Yes & 100 & 0.2205 & 22.05 \\
\hline $\begin{array}{c}\text { Ongoing } \\
\text { communication with } \\
\text { SMEs and partners? }\end{array}$ & No & 0 & 0.1929 & 0 \\
\hline $\begin{array}{c}\text { Monitoring of public } \\
\text { opinion data and other } \\
\text { research? }\end{array}$ & Yes & 100 & 0.1614 & 16.14 \\
\hline \multicolumn{2}{|c|}{ Monitoring event value } & 61.81 \\
\hline
\end{tabular}


The event monitoring group, in the example, integrates media monitoring, exchanges with different organizations, and public opinion monitoring. Combining the weighted values of the elements through a summation equation results in a monitoring event value of 61.81 (Table 5). The tree organization for the PPI allows assessors to use the same approach to calculate the values of the different groups of components for each level, culminating - through the additive process - in an overall PPI value. Each element in a grouping is attributed a weight using an elicitation process to define its relative importance in comparison with its pair elements. This way, the value of each group of elements in each level can be calculated by using the weighted sum of its components in the level below. Level 4 characteristics are aggregated into level 3 capabilities, level 2 components, level 1 functions, and finally an overall PPI value. Values for each of the eight Level 1 functions are aggregated to define an overall PPI, as in the example in Table 6.

Table 6: $\quad$ PPI (illustrative).

\begin{tabular}{|l|c|c|c|}
\hline \multicolumn{1}{|c|}{$\begin{array}{c}\text { Public Preparedness Functions } \\
\text { (Level 1) }\end{array}$} & $\begin{array}{c}\text { Level 1 } \\
\text { Weight }\end{array}$ & $\begin{array}{c}\text { Level 1 } \\
\text { Index }\end{array}$ & $\begin{array}{c}\text { Weighted } \\
\text { Index }\end{array}$ \\
\hline $\begin{array}{l}\text { Disaster public education } \\
\text { programs }\end{array}$ & 0.1587 & 72.38 & 11.49 \\
\hline Public information & 0.1428 & 67.45 & 9.63 \\
\hline Public health programs & 0.1111 & 69.63 & 7.74 \\
\hline Health care & 0.0952 & 55.43 & 5.28 \\
\hline Community engagement & 0.1033 & 37.85 & 3.91 \\
\hline Warning/notification systems & 0.1349 & 60.62 & 8.18 \\
\hline Evacuation resources & 0.1270 & 63.52 & 8.07 \\
\hline Community shelters & 0.1270 & 57.43 & 6.89 \\
\hline Overall PPI & & 61.19 \\
\hline
\end{tabular}

The disaster public education program variable was selected by SMEs as the most important of the eight functions when considering how a community impacts public preparedness, with an associated weight of 0.1587 . The next most important function is the public information capability, which has a weight of 0.1428 , followed by warning/notification systems at 0.1349 , evacuation resources and community shelters at 0.1270 , public health programs at 0.1111 , community engagement at 0.1033 , and finally, health care, with a weight of 0.0952 .

The community characterized in this example has a fairly robust disaster public education program (hazard identification, risk assessment and hazard awareness), public health program (disease prevention, food safety, and health education), public information (risk and crisis communication, public point of contact), and evacuation resources (evacuation plans and routes). Notification systems (disaster warning systems, public notification systems, and health alert 
systems), health care (medical assets, surge capability, and mass casualty/ mortuary affairs support), and community shelters (community shelter management plan, evacuee shelter management plan, and facilities) have values between 50 and 60 , which means that the community has diverse elements in place to fulfill these missions, but significant enhancement is still possible. Community engagement has the lowest value, 37.85, which means the community does not have robust public/private partnerships and may lack the presence of citizen groups, such as local emergency planning committees or community response teams.

By multiplying the value of level 1 functions by their weights, researchers can obtain the weighted values. The sum of these weighted values gives the overall PPI index. For example, by multiplying the disaster public education programs index (72.38) by its weight (0.1587), we obtain a weighted disaster public education programs index of 11.49 . This value is added to the other weighted index values of public preparedness functions to obtain an overall PPI of 61.19 (Table 6).

This method of characterizing the capabilities of a community to support the preparation of citizens allows for consideration of how capabilities vary within the sector as a whole. A score of 100 on the PPI is not necessarily the expected level of capability for public preparedness. Rather, a score of 100 would represent an optimal community that would rarely be observed. An expected level of capability would come not from a pre-fixed number on the index, but rather from an analysis of the average preparedness score of similar communities, combined with examination of minimally accepted capabilities from within each of the Level 1 and 2 variables.

The PPI, based on a community's programs, plans, and resources in terms of public preparation, is also useful to integrate into separate programs that characterize the overall resilience of a community or an even larger geographic region.

\subsection{Visualization and comparison of PPI values}

Although an individual PPI is important with regard to the data it represents, it can be difficult to fully interpret without a frame of reference. For instance, does an overall PPI score of 61.19 mean that a community and its citizens are well prepared to respond to an emergency? The question cannot be answered without an understanding of how the PPI compares with other scores. The value of a PPI is strongly related to the community and its demographics and hazard profile. A comparative framework is thus necessary. Using a PPI value to compare similar communities in terms of their regional resilience can provide additional vital benefits. To facilitate comparisons between different possible actions, municipal or county officials need tools that allow them to consider possible options for enhancement, define changes in characteristics at each level, and immediately see the potential changes to the overall values of the calculated indices. The PPI can also be used to aid communities in assessing their current capabilities, as well as laying out a systematic approach to improving capabilities by targeting 
specific areas of weakness. The index can also be combined with other elements to characterize the resilience of a region, as described in the next section.

\section{Using the PPI to assess regional resilience}

Community resilience or regional resilience can be defined as the capability of a geographic location, its inhabitants, and its organizations to anticipate risk, limit impact, and recover rapidly through survival, adaptability, evolution, and growth in the face of turbulent change [14]. To fully measure regional resilience, researchers must account for all component parts (e.g., people, institutions, and organizations). To do so, they often separate the topic into two main aspects to be analyzed: soft and hard [1]. In soft aspects, consideration of the population preparedness is important. Beyond its own benefits, the PPI also complements different indices that have been developed by Argonne to assess the protection, vulnerability, resilience, and criticality of facilities, combined with information about the susceptibility of assets to specific threat types $[2,16]$. By combining these indices with other tools developed to assess the resilience of individual community subsystems - leading to more specific assessment of the soft aspects of regional resilience - it is possible to form a more thorough representation of specific area resilience and of risk in general.

\section{Conclusion}

In a complex and interconnected world, it is vital for communities to enhance public protection and resilience. Preparing the public to face an emergency is uniquely important because safety and high quality of life are the ultimate goals of a community. Therefore, it is essential to consider how communities can support and enhance the preparedness and resilience of their citizens. The proposed PPI, based on accepted programmatic elements, allows for consideration of the particular capabilities of a community to support the preparation of its population in a global methodology to assess regional resilience.

\section{References}

[1] U.S. Department of Homeland Security, 2009, Resilience - Concept Development: an Operational Framework for Resilience, Science and Technology Directorate, Arlington, DC, $52 \mathrm{p}$.

[2] Argonne National Laboratory, 2010, Constructing a Resilience Index for the Enhanced Critical Infrastructure Protection Program, ANL/DIS-10-9, Decision and Information Sciences Division, Argonne National Laboratory, Argonne, Illinois, USA, $35 \mathrm{p}$.

[3] CARRI, 2010, Community \& Regional Resilience Institute, Oak Ridge National Laboratory, Oak Ridge, TN, available at http://www.resilientus.org/ (accessed December 27, 2010). 
[4] ResOrgs, 2010, Resilient Organizations, New-Zealand, available at http://www.resorgs.org.nz/index.shtml (accessed December 27, 2010).

[5] National Infrastructure Advisory Council, 2009, Critical Infrastructure Resilience, Final Report and Recommendations, U.S. Department of Homeland Security, Washington, D.C., 54 p.

[6] Argonne National Laboratory, 2009, Constructing Vulnerability and Protective Measures Indices for the Enhanced Critical Infrastructure Protection Program, ANL/DIS-09-4, Decision and Information Sciences Division, Argonne National Laboratory, Argonne, Illinois, USA, 41 p.

[7] The Council for Excellence in Government, 2006, Are We Ready? Introducing the Public Readiness Index: A Survey-Based Tool to Measure the Preparedness of Individuals, Families and Communities, Washington, D.C., 26 p.

[8] FEMA, 2010, Ready.gov, Federal Emergency Management Agency, Department of Homeland Security, Washington, D.C., available at http://www.ready.gov (accessed December 27, 2010).

[9] HSEMA, 2010, 72hours, Homeland Security and Emergency Management Agency, Washington, D.C., available at http:/www.72hours.dc.gov (accessed December 27, 2010).

[10] City of Chicago, 2010, Alert Chicago, City of Chicago, Chicago, IL, available at http://www.alertchicago.org (accessed December 27, 2010).

[11] Citizen Corp, 2009, Personal Preparedness in America: Findings from the 2009 Citizen Corps National Survey - Summary Sheet, Federal Emergency Management Agency, Washington, D.C., 8 p.

[12] Dyers, J., 2005, "MAUT - Multi-attribute utility theory," International Series in Operations Research \& Management Science, 1, Volume 78, Multiple Criteria Decision Analysis: State of the Art Surveys, IV, pp. 265292

[13] Keeney, R.L., 1992, Value-Focused Thinking: A Path to Creative Decisionmaking, Harvard University Press, Cambridge, MA.

[14] Keeney, R.L., and Raiffa, H., 1976, Decisions with Multiple Objectives: Preferences and Value Tradeoffs, John Wiley and Sons, New York, NY. 